\title{
Millennial Scale Variability of the East Asian Winter Monsoon Before the Last Glacial-Interglacial Cycle
}

Grain size measurement on samples from a typical loess-palaeosol sequence on the central Chinese Loess Plateau are used to reconstruct the Pleistocene East Asian monsoon climate. The coarsegrained fraction, i.e. the weight percentage $>30 \mathrm{~mm}$, of the bulk grain size distribution is used as a sensitive proxy for East Asian winter monsoon strength ( $\mathrm{Lu}$ et al., 1997). On the basis of an absolute time scale (Vandenberghe et al., 1997; Huissteden et al., 1997), time series variations of this proxy show that winter monsoon strength varied on millennial time scales during the periods 145-165, 240-280, 320-350, 390-440, 600-640, 860-890, 900-930 and 1330-1400 kyr BP (Fig. 1), these changes can not be explained by the orbital forcing. The wavelength of these climatic oscillations varied between 1.89 and $4.0 \mathrm{kyr}$, as is shown by spectral analysis using the multi-taper method. Although numerical simulation experiments show that high frequencies can also arise from measurement errors in the grainsize analysis, the frequencies prove to be stable when the spectral analysis is repeated with a different number of tapers. For the time being, we do not correlate these climatic oscillations with paleoclimatic records in the North Atlantic deep-sea sediments because both time scale require further improvement. However, our data certainly demonstrate that millennial scale East Asian winter monsoon variations in the last 1.4 million years can be detected from terrestrial loess records.

\section{Reference}

Journal of Quaternary Science, 14(2):101-110, 1999

\section{Huayu Lu, Zhisheng An}

State Key Laboratory of Loess and Quaternary Geology, Chinese Academy of Sciences, Xi'an, China

\section{Ko van Huissteden, Govert Nugteren, Jef} VANDENBERGHE

Faculty of Earth Science, Free University, Amsterdam, The Netherlands

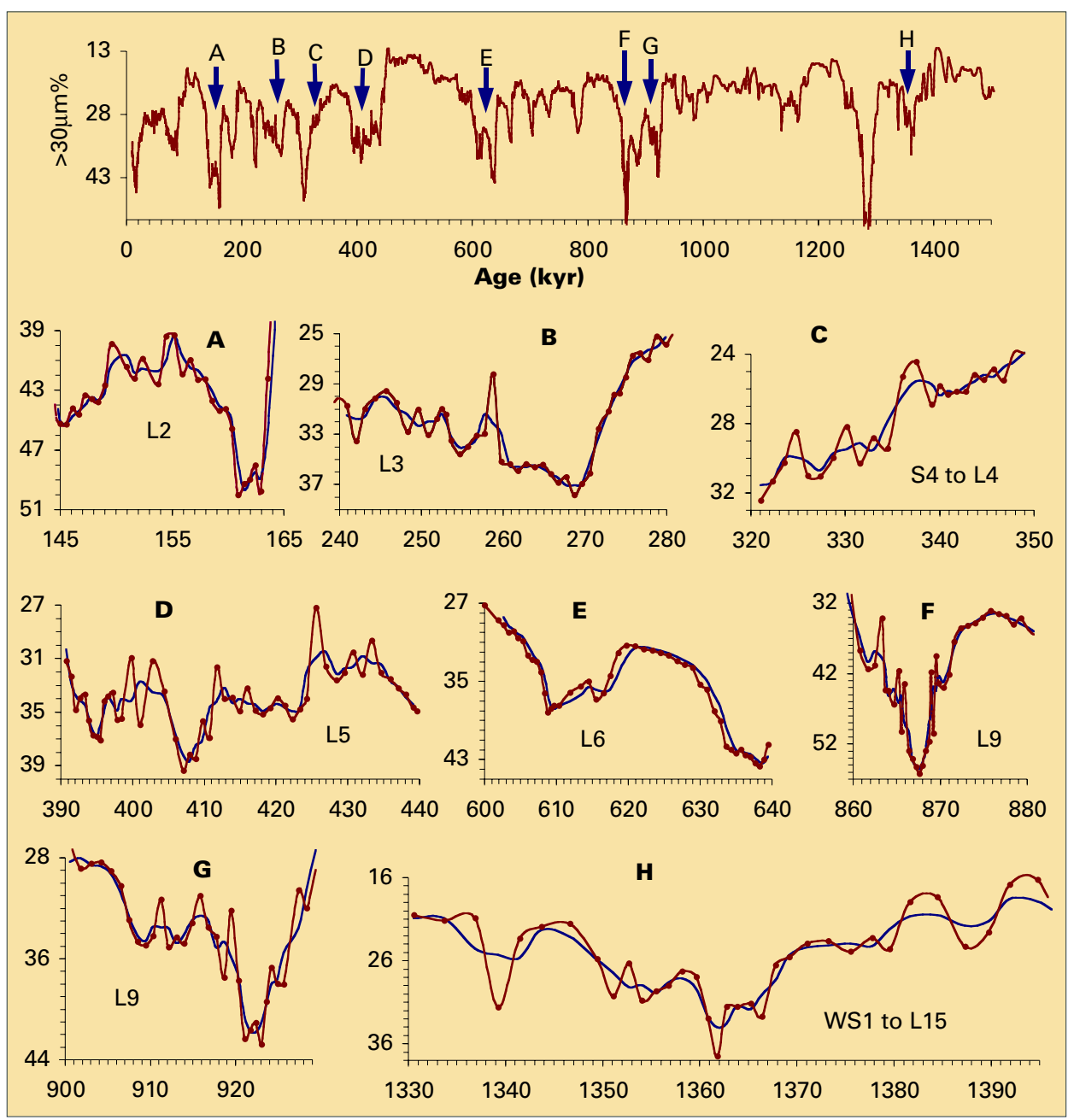

Figure 1: Changes in proxy indicator of winter monsoon strength over the past $1500 \mathrm{kyr}$. The lower plots are are enlarged sections of the time series as indicated by capital letters.

\section{START Young Scientist Award Program}

To recognize the achievements of outstanding young scientists from developing countries in Africa, Asia and Oceania, the International START Secretariat is requesting nominations for the START Young Scientist Award Program. Award decisions will be based on a journal article published by the young scientist (preferably in English). In keeping with START's mission of conducting research on regional aspects of global change, the article should focus on some aspect of global change research that is being conducted on a regional level or has a strong regional focus.

Awards, which include an honorarium, will be made to scientists from developing countries in each of the START regions: Africa, South Asia, Southeast Asia, East Asia and Oceania. Award announcements are expected to be made in August 2000.

Applicants for the START Young Scientist Awards must be 40 years of age or younger. In the case of multi-authored articles, the applicant should be the lead author of the article. The article should have been published within the last two years.
Recipients of START Fellowship/Visiting Scientist Awards are strongly encouraged to submit articles they may have published based on research conducted with START support. Articles will be reviewed in consultation with the respective START Regional Centers/Secretariats and by a special review committee. Applicants or nominators should submit one journal article and a brief biography to:

Ms. Amy Freise, Program Coordinator International START Secretariat 2000 Florida Avenue, NW, Suite 200

Washington, DC 20009 USA

Phone: (+1-202) 462-2213

Fax: (+1-202) 457-5859

E-mail: afreise@agu.org

The deadline for submission of nominations/ applications is June 16,2000.

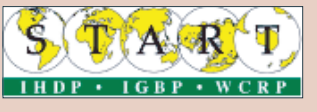

